\title{
IaB diamond and its geological implications
}

\author{
Tingting Gu, Wuyi Wang \\ Gemological Institute of America, $50 \mathrm{~W} 47^{\text {th }}$ Street, New York City, NY 10036, USA
}

\section{Introduction}

Nitrogen is one of the most common impurities in diamonds, and its aggregation styles in diamonds have been used as criteria for diamond classification. Among all diamond types, Ia is the most common type in nature, including type $\mathrm{IaA}, \mathrm{IaAB}$ and $\mathrm{IaB}$. However, pure $\mathrm{IaB}$ (with $100 \% \mathrm{~B}$ aggregation) diamonds are rather rare. Some of them are found in diamond suites that are related with super deep origin (Buffalo Hills, Eurelia, Sao Luis, Rio Soriso, Kankan, Jagersfontein Kimberlite, etc.) or oldest diamondiferous rocks (Wawa), others can be found occasionally in alluvial diamonds (Arenapolis, Boa Vista, Namibia) or at the base of lithosphere with deformation features (Argyle). The origin and formation of those diamonds are mainly mysterious. The nitrogen concentration of those diamonds can be very low (less than 200 ppm, i.g., Eurelia, Sao Luis, Buffalo Hills), and they can mix with type IIa diamonds in the same stone with large size. Experimental data shown that $\mathrm{C}$ center in diamonds can be gradually changed to A center and to B center (Evans \& Qi, 1982) by hightemperature annealing, with parallel formation of the platelet in $\{001\}$ planes. Therefore, the occurrence of B center and low nitrogen concentration has often been interpreted as a sign of high temperature and probably longer geological time for the host diamond. However, for many pure IaB diamonds, the platelet defects can be degraded completely (Buffalo Hills), which have been termed as irregular diamonds (Woods \& Collins, 1986), indicating that they could have undergone unusual geological event during the diamond forming process. Previous studies proposed that platelet degradation in these diamonds results in formation of octahedral voidites and dislocation loops lying in the $\{001\}$ planes (Evans et al., 1995). Those voidites could provide a milky/hazy appearance to the IaB diamonds and contain mantle-derived fluids but their physical and chemical properties are still controversial.

To understand the formation and geological implications of type IaB diamonds, we systematically studied their defects and deformation features by FTIR, cathodoluminesence, photo-luminescence spectroscopy, and examined their inclusions by Raman spectroscopy. We obtained evidence of the sublithospheric origin of a majority of IaB diamonds, and their interaction with deep hydrocarbon and carbonate fluids, which might be important to interpret the recycling of nitrogen in deep Earth.

\section{Results}
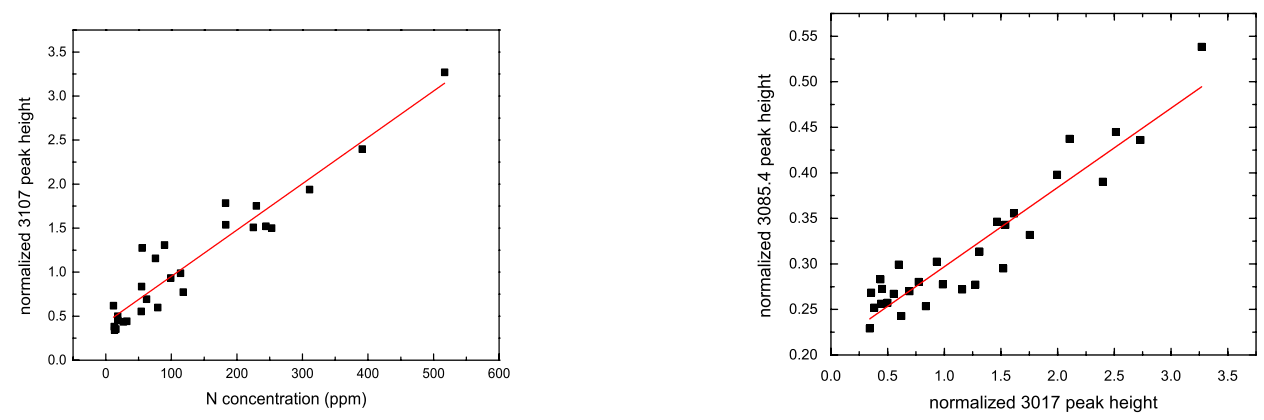

Figure 1 (Left) Nitrogen concentration determined by FTIR as a function of hydrogen concentration constrained by normalized 3107 peak height. (Right) Normalized 3107 peak height as a function of 3085.4 peak height. (Peak height at $3107 \mathrm{~cm}^{-1}$ and $3085.4 \mathrm{~cm}^{-1}$ have been normalized by diamonds peak at $2460 \mathrm{~cm}^{-1}$ )

We examined about $69 \mathrm{IaB}$ diamonds ranging from 0.2 ct to $\sim 100 \mathrm{ct}$, and most of them (97\%) shown the degradation of the platelet peaks, while 38 diamonds show micro inclusions detectable by Raman 
spectroscopy. Nitrogen concentration ranges from $4 \mathrm{ppm}$ to $516 \mathrm{ppm}$ determined by FTIR spectra. Hydrogen peaks at $3107 \mathrm{~cm}^{-1}$ have been detected, which shows a linear correlation with nitrogen concentration (Fig. 1). We observed the peak at $3085.4 \mathrm{~cm}^{-1}$ featured by $\mathrm{IaB}$ diamonds with milky appearance or cloudy inclusions; in contrast, this peak is missing among more than $90 \%$ of IaB diamonds without detectable cloudy inclusions. We normalized the peak height at $3107 \mathrm{~cm}^{-1}$ and $3085.4 \mathrm{~cm}^{-1}$ to diamond peak at $2460 \mathrm{~cm}^{-1}$, and observed a linear correlation of the two peaks (Fig. 1). However, no correlation of the peak height at $3085.4 \mathrm{~cm}^{-1}$ and $3107 \mathrm{~cm}^{-1}$ has been observed for the greyish or violet type IaAB diamonds. Therefore, the peak at $3085.4 \mathrm{~cm}^{-1}$ could be a typical optical feature for the milky IaB diamond, which might be related with the VN3H defects (Goss et al., 2014) and $\mathrm{B}$ aggregation.
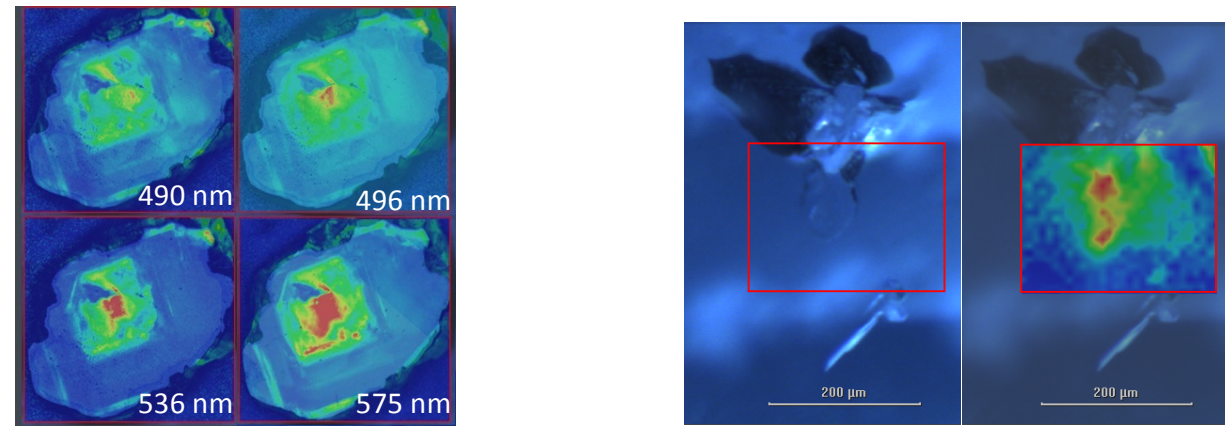

Figure 2 (Left) Diamond defect maps of photo-luminescence (PL) spectra taken with 455 and $532 \mathrm{~nm}$ excitations at liquid-nitrogen temperature. (Right) PL mapping of the $536 \mathrm{~nm}$ defect around the fracture area alongside a walstromite inclusion.

From cathodoluminesence (CL) images of the IaB diamonds, we found about half of them show dislocation networks and deformation features, indicating they have been brought up from deep Earth and experienced plastic deformation under high-pressure conditions. Photo-luminescence spectra have been taken at liquid-nitrogen temperature. Among 69 stones we examined, we observed $\sim 90 \% \mathrm{IaB}$ milky diamonds contain $536 \mathrm{~nm}$ defect, in contrast with IaB diamonds with no distinct cloudy features among which less than $30 \%$ showing $536 \mathrm{~nm}$ defects. In a IaB diamond with cloudy zone in the center, we observed $490 \mathrm{~nm}, 496 \mathrm{~nm}, 536 \mathrm{~nm}$, and $575 \mathrm{~nm}$ defects in the cloudy center compared with the relatively clean surrounding area (Fig. 2). The $536 \mathrm{~nm}$ defect has also been observed in the discoid fracture alongside a walstromite inclusion, which might be caused by high temperature plastic deformation (Fig. 2). Therefore, presence of $536 \mathrm{~nm}$ defects in most milky IaB diamonds may indicate a certain dislocation style associated with high temperature.

By examining systematically the mineral inclusions in those diamonds, we found more than three quarters of them are from sublithosphere, indicated by inclusions that might be fragments of transition zone and lower mantle. Walstromite, larnite, titanite, coesite, Ca-perovskite assemblages have been found for more than half of the IaB diamonds, which indicates they originate as deep as the transition zone area. The equilibrium of the Ca-silicate inclusions imply that the initial $\mathrm{Ca}$-silicate inclusions were trapped by diamond growth at conditions near to the $\mathrm{CaSiO}_{3}$-walstromite $\rightarrow$ larnite $(\beta$ $\left.\mathrm{Ca}_{2} \mathrm{SiO}_{4}\right)+\mathrm{CaSi}_{2} \mathrm{O}_{5}$-titanite equilibrium phase boundary, which begins above $10 \mathrm{GPa}$ and $1773 \mathrm{~K}$ (Anzolini et al., 2016). Besides, we observed ferropericlase in several IaB diamonds, coexisting with walstromite and Ca-perovskite, indicating a superdeep origin of its host diamonds. We also found jeffbenite (TAPP) in three typical IaB diamonds, either as separate phase or coexisting with enstatite pyroxene and walstromite. The well preserved rhombus shape of the jeffbenite inclusion (Fig. 3) indicates that it could be a syngeneic inclusion with the host diamond forming in the lower mantle as bridgmanite while retrograde to current phase. In addition, spinel phase which has been considered as retrogressed calcium ferrite (CF) structured phases with high Al content at upper lower mantle (Walter et al., 2011) was observed coexisting with enstatite pyroxene phase in several milky IaB diamonds with relatively high hydrogen concentration. Interestingly, we found calcite and dolomite inclusions in six IaB diamonds coexisting with walstromite or as separate phases, with calcite phase in a well-crystallized rhombus shape suggesting their syngeneic character. The coexisting walstromite 
phase indicates their deep origin and implies that a carbonate-rich fluid has been involved during the diamond forming process in the transition zone. Moreover, methane has been detected coexisting with carbonate phases in a IaB diamond with low nitrogen concentration $(4 \mathrm{ppm})$. In this typical diamond, calcite, dolomite, magnetite, ferropericlase, spinel, nepheline and corundum have been detected by Raman spectroscopy. Methane has been detected in the fluid jacket in several inclusions (Fig. 3). Coexisting of methane and carbonate phases could confirm the former experimental evidence of the production of methane through the reaction $\mathrm{CaCO}_{3}+\mathrm{H}_{2} \mathrm{O}+\mathrm{FeO} \rightarrow \mathrm{CH}_{4}+\mathrm{CaO}+\mathrm{Fe}_{3} \mathrm{O}_{4}$ under mantle conditions (Scott et al., 2004).
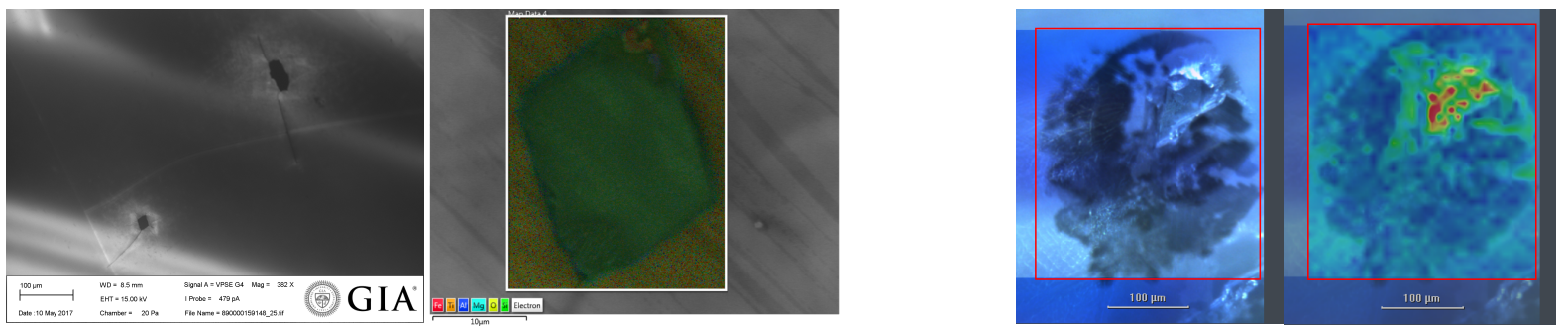

Figure 3 (Left) CL image of a diamond with jeffbenite (TAPP) phase on the surface and the chemical mapping of the smaller one with rhombus shape. (Right) Raman mapping of the methane peak at $\sim 2913 \mathrm{~cm}^{-1}$ in a diamond inclusion with spinel and nepheline.

\section{Discussions}

Combined with FTIR, Raman spectroscopy and the luminescence optical features, formation of IaB diamonds may take place in the transition zone and lower mantle region where large size pure IaB diamonds ( $5 \mathrm{ct}$ up to $100 \mathrm{ct}$ ) can form. Absence of the platelet peak and presence of the $536 \mathrm{~nm}$ defect for most milky IaB diamonds indicates they have experienced high temperature during their residence in the deep Earth, which could take a long geological time suggested by the full aggregation of B center. The FTIR features of the IaB diamonds suggests a $\mathrm{N}-\mathrm{H}$ rich fluid has been involved during the diamond formation process, which could reach as deep as the lower mantle in ancient geological time. Compared with nitrogen free sublithospheric diamonds (such as IIa diamonds with metallic inclusions, Evan et al., 2016), inclusions in the pure IaB diamonds suggests they could form from C$\mathrm{O}-\mathrm{H}$ system that might be more compatible with nitrogen.

\section{References}

Anzolini C, Angel RJ, Merlini M, Derzsi M, Tokár K, Milani S, Krebs MY, Brenker FE, Nestola F, Harris JW (2016) Depth of formation of CaSiO3-walstromite included in super-deep diamonds. Lithos, 1-10

Evans T, Kiflawi I, Luyten W (1995) Conversion of platelets into dislocation loops and voidite formation in Type IaB diamonds. Proceedings: Mathematical and Physical Sciences 499(1936): 295-313

Evans T, Qi Z (1982) The Kinetics of the Aggregation of Nitrogen Atoms in Diamond. Proceedings of the Royal Society A: Mathematical, Physical and Engineering Sciences 381, 159-178

Smith EM, Shirey SB, Nestola F, Bullock ES, Wang J, Richardson SH, Wang W (2016) Large gem diamonds from metallic liquid in Earth's deep mantle. Science 354 (6318): 1403-1405

Goss JP, Briddon PR, Hill V, Jones R, Rayson MJ (2014) Identification of the structure of the 3107 $\mathrm{cm}^{-1} \mathrm{H}$-related defect in diamond. J. Phys.: Condens. Matter 26, 145801

Scott HP, Hemley RJ, Mao H (2004) Generation of methane in the Earth's mantle: in situ high pressure-temperature measurements of carbonate reduction, Proceedings of the National Academy of Sciences 101(39): 14023-14026

Walter MJ, Kohn SC, Araujo D, Bulanova GP, Smith CB, Gaillou E, Wang J, Steele A, Shirey SB (2011) Deep Mantle Cycling of Oceanic Crust: Evidence from Diamonds and Their Mineral Inclusions. Science 334, 54-57

Woods GS, Collins AT (1986) Platelets and the infrared absorption of type Ia diamonds. Proceedings of the Royal Society of London A 407, 2109-2238 